\title{
Radiation-inducible silencing of uPA and UPAR in vitro and in vivo in meningioma
}

\author{
VENKATESWARA RAO GOGINENI ${ }^{1}$, ARUN KUMAR NALLA ${ }^{1}$, RESHU GUPTA ${ }^{1}$, \\ BHARATHI GORANTLA ${ }^{1}$, MEENA GUJRATI ${ }^{2}$, DZUNG H. DINH ${ }^{3}$ and JASTI S. RAO ${ }^{1,3}$ \\ Departments of Cancer Biology and Pharmacology ${ }^{1}$, Pathology ${ }^{2}$ and Neurosurgery ${ }^{3}$ \\ University of Illinois College of Medicine at Peoria, One Illini Drive, Peoria, IL 61605, USA
}

Received November 9, 2009; Accepted December 29, 2009

DOI: 10.3892/ijo_00000557

\begin{abstract}
Stereospecific radiation treatment offers a distinct opportunity for temporal and spatial regulation of gene expression at tumor sites by means of inducible promoters. To this end, a plasmid, pCArG-U2, was constructed by incorporating nine CArG elements (in tandem) of EGRl gene upstream to uPA and UPAR siRNA oligonucleotides in a pCi-neo vector. Radiation-induced siRNA expression was detected in a meningioma cell line (IOMM-Lee). Immunoblotting and RT-PCR analyses confirmed downregulation of uPA and uPAR. A similar effect was observed in transfected cells followed by $\mathrm{H}_{2} \mathrm{O}_{2}$ treatment. Moreover, pre-treatment of transfected cells with $\mathrm{N}$-acetyl L-cysteine blocked the silencing of UPA and UPAR, which further confirmed the oxidative damage-mediated downregulation. Cell proliferation assays and Western blot analysis for apoptotic molecules confirmed cell death in a radiation-inducible fashion. Migration and Matrigel invasion assays also revealed a marked decrease in migration and invasion. Immunocytochemistry showed a marked decrease in UPA and UPAR levels in transfected and irradiated cells. H\&E staining revealed a decrease in the preestablished tumor volume among the animals treated with pCArG-U2 and radiation. Immunohistochemistry of the brain sections established with intracranial tumors also revealed a marked decrease in UPA and UPAR in a radiation-inducible fashion. Taken together, our data suggest pCArG-U2 as a suitable candidate for radiation-inducible gene therapy.
\end{abstract}

\section{Introduction}

Advancements in radiation treatment regimens, such as intensity-modulated radiation therapy and image-guided fourdimensional radiation therapy, have increased the precision

Correspondence to: Professor Jasti S. Rao, Department of Cancer Biology and Pharmacology, University of Illinois College of Medicine, One Illini Drive, Peoria, IL 61605, USA

E-mail: jsrao@uic.edu

Key words: uPA, uPAR, siRNA, radiation inducible promoter, CArG elements, meningioma of dose delivery to the tumor site while limiting exposure to surrounding normal tissues. Apart from the proven efficiency of curative radiation therapy, evasive strategies adopted by the cancer cells to become radioresistant and the fact that radiotherapy is generally useful against tumors that have not metastasized, invite sensitization or combination methods of treatment. Reports of radioresistance and radiation-induced invasive and angiogenic characteristics in gliomas and other brain cancers have been gaining significance $(1,2)$. Accordingly, strategies exploiting concomitant administration of radiotherapy along with cytotoxic chemotherapy and radiosensitization drugs or inhibitors of cellular repair processes and/or tumor cell proliferation have evolved. However, toxicity to normal tissue or differential sensitization among malignant versus normal cells are the issues that have not yet been addressed. On the other hand, the precision of radiation treatment provides a potential opportunity to utilize tumorspecific and inducible promoter systems with therapeutic genes that kill tumor cells when expressed $(3,4)$.

The simultaneous use of ionizing radiation and gene therapy, which targets tumor cells via independent cytotoxic actions, additively minimizes the evolution of resistant cells and even eliminates the otherwise radioresistant cells. Gene therapy targeted by radiation is a concept in which the complementary DNA for a cytotoxic gene is ligated downstream of a radiation-inducible promoter. Although still in its infancy, a number of clinical gene therapy trials have already been conducted (5). The induction of early response by ionizing radiation involves the expression of immediate early genes that code for transcription factors (e.g., Fos, Jun, AP-1, $\mathrm{NF}-\kappa \mathrm{B})$ as well as cytokines and growth factors [e.g., early growth response factor-1 (EGR-1)] (6,7). Among the genes whose expressions are induced by ionizing radiation, the promoters of EGR-1 (8), p21 (9) and others (10,11) have been successfully used to control gene expression by ionizing radiation in both in vitro and in vivo experiments. Functional analysis of the $E G R-1$ gene demonstrates that the DNA sequences that drive the radiation-inducible response are located in the enhancer region of the consensus sequence $\mathrm{CC}(\mathrm{A} / \mathrm{T}) 6 \mathrm{GG}$, also known as CArG elements. This promoter was able to control spatial and temporal expression of suicide genes such as TNF- $\alpha$ (12) and caspase 8 (13). Joki et al (14) have shown the radioenhancibility of the EGR-1 promoter in 
glioma cells by attaching the luciferase reporter gene to EGR-1 (EGR-Luc). For optimal delivery, the shortening of the promoter sequence without loss of response is very attractive for gene therapy use due to the limitations in vector capacity to accommodate large inserts. Also, synthetic promoters lack the binding sites for potentially antagonistic transcription factors seen in the native EGR-1 promoter that could restrict radioresponsiveness. The development of synthetic promoters is a means of inhibiting non-radiationinduced transcription factors and ensuring the response is selectively radiation-stimulated. The four-CArG element cassette (E4) has been cloned upstream of the GFP reporter gene to investigate its radioinducibility in transfected human breast adenocarcinoma (MCF-7) as well as human glioma cells (U87-MG) (15). A synthetic construct (pE9), which incorporates nine radiosensitive $\mathrm{CArG}$ elements from the EGR-1 promoter, has recently been developed to drive expression of the $i N O S$ gene for experimental gene therapy (16). The combination of gene therapy and radiation treatment may enhance inducibility of apoptosis and cytotoxicity, which could also compensate for the weak activity of specific promoters.

The uPA-uPAR system, which controls the formation and activity of plasmin, plays a key role in modulating homeostasis, thrombosis, cell adhesion, migration and several other biological processes. While a great deal is known about the physiological function of the UPA-uPAR system, its functional redundancy in pathogenesis has been recently recognized, particularly in tumor progression. uPA and uPAR have been implicated in tumor cell invasion, migration, proliferation and metastasis in different cancers including glioma, meningioma and prostate cancer (17-19). Elevated levels of these factors in tumor tissue are associated with tumor aggressiveness and poor patient outcome and are a major cause of treatment failure. Both are used as diagnostic markers as well as therapeutic targets due to their aberrant and unique expression pattern during cancer progression $(20,21)$. As such, uPA and uPAR are critical candidates for therapeutic targeting. RNAi-mediated knockdown of uPA and UPAR has been shown to be very effective in impeding the aggressive characteristics of cancer cells in vitro and in vivo $(17,19)$. Further, downregulation of these molecules has led to pro-apoptotic signaling in different cancer cells (22). Here, we found that radiation-induced gene therapy offers a very promising strategy for cancer treatment; in the present study, we have exploited the radiation-inducibility of CArG sequences in driving siRNA expression to silence uPA and UPAR in vitro and in vivo.

\section{Materials and methods}

Cell culture conditions. For the present study, we used the human meningioma cell line IOMM-Lee (kindly provided by Dr Ian E. McCutcheon, University of Texas M.D. Anderson Cancer Center, Houston, TX). Cells were maintained in Dulbecco's modified Eagle's medium (Mediatech, Herndon, VA), which was supplemented with $10 \%$ fetal bovine serum, $100 \mu \mathrm{g} / \mathrm{ml}$ streptomycin and $100 \mathrm{U} / \mathrm{ml}$ penicillin (Invitrogen, Carlsbad, CA). Cells were maintained in a humidified atmosphere containing $5 \% \mathrm{CO}_{2}$ at $37^{\circ} \mathrm{C}$. Cells were treated with
$\mathrm{N}$-acetyl-L-cysteine (Sigma, St. Louis, MO) and hydrogen peroxide (Sigma) and incubated for the indicated period of time in serum-free medium. uPA, uPAR, PARP, XIAP and GAPDH antibodies were purchased from Santa Cruz Biotechnology (Santa Cruz, CA).

Plasmid construction. The pCi-neo plasmid (Promega, Madison, WI) was used as the basis for the vector constructs. A synthetic enhancer containing nine tandemly repetitive CArG elements (CCATATAAGG) was cloned as doublestranded molecule derived by annealing the complementary single-stranded oligonucleotides having BglII and SgfI sites at the linker ends (synthesized by Integrated DNA Technologies, Coralville, IA). This created the vector pCArG with a chimeric promoter consisting of synthetic CArG enhancer and the basal CMV IE gene promoter containing the transcription start site and TATA box. Further, complementary small interfering oligonucleotide sequences for uPA and UPAR (13) were synthesized as a single oligonucleotide, annealed and cloned at the NheI and SalI sites of pCArG, resulting in the plasmid pCArG-U2.

Transfection conditions. All transfection experiments were performed with fuGene $H D$ transfection reagent as per the manufacturer's protocol (Roche, Madison, WI). Cells were transfected with plasmid constructs in $2 \mu \mathrm{g}$ DNA to $3 \mu \mathrm{l}$ reagent ratio. After $6 \mathrm{~h}$ of transfection, complete medium was added and kept for $24 \mathrm{~h}$ and used for further experiments.

Radiation treatment. The RS 2000 Biological Irradiator ( $\mathrm{Rad}$ Source Technologies, Inc., Boca Raton, FL) X-ray unit, which was operated at $150 \mathrm{kV} / 50 \mathrm{~mA}$, was used for radiation treatments. Cells were given a single dose of radiation (either 5 or $10 \mathrm{~Gy}$ ) after $24 \mathrm{~h}$ of transfection with the plasmid.

Reverse transcription PCR. The cells were transfected and irradiated as described above, and total RNA was extracted as described by Chomczynski and Sacchi (23). PCR was performed using a reverse transcription PCR (RT-PCR) kit (Invitrogen): 35 cycles of denaturation at $94^{\circ} \mathrm{C}$ for $1 \mathrm{~min}$, annealing at $67^{\circ} \mathrm{C}$ for $30 \mathrm{sec}$, and extension at $72^{\circ} \mathrm{C}$ for $90 \mathrm{sec}$ with the primer for uPA, UPAR and GAPDH as described by Pulukuri et al (24). The expected PCR products were visualized using ethidium bromide after resolving on $2 \%$ agarose gels. RT-PCR for glyceraldehyde-3-phosphate dehydrogenase (GAPDH) was performed to normalize input RNA.

Western blot analysis. Protein extracts were obtained from the cells using Tris-buffered lysis buffer (Tris-buffered saline, $20 \mathrm{mM}$ EDTA, 0.1\% Triton X-100). Cell lysates were also collected from untreated cells that were cultured and maintained under similar conditions (mock). Protein concentration was determined using a bicinchoninic acid procedure (Pierce, Rockford, IL). Equal amounts of protein were then subjected to SDS-PAGE using gels with appropriate percentage of acrylamide followed by transfer of protein to polyvinylidene difluoride membranes (Bio-Rad, Hercules, CA). Membranes were then blocked in 5\% non-fat dry milk in phosphatebuffered saline (PBS) and incubated overnight at $4^{\circ} \mathrm{C}$ with primary antibodies in blocking solution (1:1000 dilution). 
Membranes were then washed twice (15 min per wash) with T-PBS [Tween-20 (0.1\%), phosphate-buffered solution]. Horseradish peroxidase (HRP)-conjugated secondary antibodies (Santa Cruz Biotechnology) were used at a 1:2000 concentration. The membranes were developed following an enhanced chemiluminescence protocol (Amersham Biosciences, Piscataway, NJ). The membranes were further probed for GAPDH, which was used as a loading control.

MTT proliferation assay. Cells were grown in 6-well plates and transfected with pCArG-U2 as described above. Twelve hours after transfection, cells were serum-starved for $6 \mathrm{~h}$ and irradiated with $10 \mathrm{~Gy}$. Six hours later, cells were trypsinized, counted and seeded at $5 \times 10^{3}$ cells per well in 96-well plates ( 8 wells per treatment group). After the indicated hours of incubation in conditioned medium, $20 \mu \mathrm{l}$ of MTT reagent were added to the cells, followed by another $4 \mathrm{~h}$ of incubation at $37^{\circ} \mathrm{C}$. Acid-isopropanol $(0.04 \mathrm{M} \mathrm{HCl} /$ isopropanol) was added to all wells and mixed vigorously so that the formazan crystals dissolved effectively. Absorbance was measured on a microtiter plate reader (Model 680, BioRad) with a test wavelength of $550 \mathrm{~nm}$ and a reference wavelength of $655 \mathrm{~nm}$.

Migration assay. IOMM-Lee cells were transfected with pCArG-U2 and irradiated as described above. After irradiation, cells were trypsinized and $5 \times 10^{4}$ cells were placed into transwell inserts with an $8-\mu \mathrm{m}$ pore size. Cells were allowed to migrate through the membrane for $24 \mathrm{~h}$ after radiation treatment. Later, cells in the upper chamber were scraped by cotton swab and the migrated cells attached to the other side were fixed, stained using the Hema-3 staining kit and counted under a light microscope as described previously (25).

Matrigel invasion assay. IOMM-Lee cells were transfected with pCArG-U2 and irradiated as described above. After irradiation, cells were trypsinized and $1 \times 10^{5}$ cells were placed onto Matrigel-coated $(1 \mathrm{mg} / \mathrm{ml})$ transwell inserts with an $8-\mu \mathrm{m}$ pore size. Cells were allowed to invade through the Matrigel for $24 \mathrm{~h}$. Later, cells in the upper chamber were removed by cotton swab. Cells adhered on the outer surface of the transwell which had invaded through the Matrigel were fixed, stained using the Hema-3 staining kit and counted under a light microscope as described previously (25).

Immunocytochemistry. Five thousand IOMM Lee cells were seeded onto 8-well chamber slides and transfected with pCArG-U2. Twenty-four hours after transfection, cells were irradiated and incubated for another $24 \mathrm{~h}$. The cells were washed, fixed with $4 \%$ buffered paraformaldehyde and permeabilized with freshly prepared $0.1 \%$ Triton X-100 containing $0.1 \%$ sodium citrate. Later, the cells were blocked with $2 \%$ BSA for $1 \mathrm{~h}$ followed by overnight incubation with uPA and uPAR antibodies (1:100 dilution) at $4^{\circ} \mathrm{C}$. Next, the chamber slides were treated with HRP-conjugated secondary antibodies (1:200) for $45 \mathrm{~min}$ at room temperature. Immunolocalization was accomplished by exposing sections to $0.05 \%$ 3,3-diaminobezidine tetrahydrochloride as the chromogen. All microscopy studies were performed using a microscope attached to a CC camera.
Animal studies. Nude mice (4-6 weeks of age) were anaesthetized, placed in a stereotactic frame (David Kopf Instruments, Tujunga, CA), and implanted with $1 \times 10^{5}$ IOMM Lee cells in $10 \mu \mathrm{l}$ of PBS through a 27 -gauge needle at $2 \mathrm{~mm}$ lateral and posterior to the bregma and $3 \mathrm{~mm}$ below the dura. After 10 days, the animals were separated into two treatment groups of 10 animals each. One group was given three doses of pCArG-U2 (1 mg/kg body weight) intracerebrally on alternate days. Simultaneously, 5 animals from each group were treated with two 5 Gy doses of radiation on alternative days between the plasmid treatments by masking the whole body with lead sheets and leaving the skull region exposed. The animals were observed for 3 weeks, euthanized and their brains fixed in buffered formaldehyde. Finally, the paraffinembedded brains were sectioned $(5 \mu \mathrm{M})$ and subjected to $\mathrm{H} \& \mathrm{E}$ and immunohistochemical staining. Animal experiments were conducted according to our institutional guidelines.

For immunohistochemical analysis, the sections were deparaffinized in xylene and rehydrated through graded ethanol. Antigen retrieval was carried out by treatment of the sections with $1 \mathrm{M}$ urea in PBS at boiling temperature for 15 min followed by quenching of endogenous peroxidase activity. The sections were blocked and later incubated overnight with UPA and UPAR antibodies (1:100 dilution) at $4^{\circ} \mathrm{C}$. Next, the sections were treated with HRP-conjugated secondary antibodies (1:200) for $30 \mathrm{~min}$ at room temperature. Immunolocalization was accomplished by exposing sections to $0.05 \%$ 3,3-diaminobezidine tetrahydrochloride as the chromogen. The slides were counterstained with Mayer's hematoxylin and mounted. All microscopy studies were performed using a microscope attached to a CC camera.

Statistical analysis. All data are presented as means \pm standard errors (SE) of at least three independent experiments (each performed at least in triplicate). One way analysis of variance (ANOVA) combined with the Tukey post-hoc test of means were used for multiple comparisons in cell culture experiments. Statistical differences are presented at probability levels of $\mathrm{p}<0.05, \mathrm{p}<0.01$ and $\mathrm{p}<0.001$.

\section{Results}

UPA and UPAR are knocked down in a radiation-inducible fashion. Transfection studies with pCArG-U2 revealed the radiation-induced knockdown of UPA and UPAR in a dosedependent manner compared to non-irradiated transfected cells (Fig. 1A). Knockdown was more pronounced when IOMM Lee cells were treated with 10 Gy radiation (Fig. 1A). Although radiation treatment was shown to elevate the levels of UPA and UPAR in IOMM Lee cells, transfection with pCArG-U2 followed by radiation treatment significantly decreased uPA and UPAR levels (Fig. 1A and B). Reverse transcription followed by amplification with specific primers also demonstrated comparable patterns of knockdown at the transcript levels (Fig. 1C and D). An increase in the transcription of UPA and UPAR was also observed with radiation treatment (Fig. 1C and D).

The inducibility of pCArG-U2 is mediated by oxidative damage. We also assessed inducibility by treating the trans- 
A)

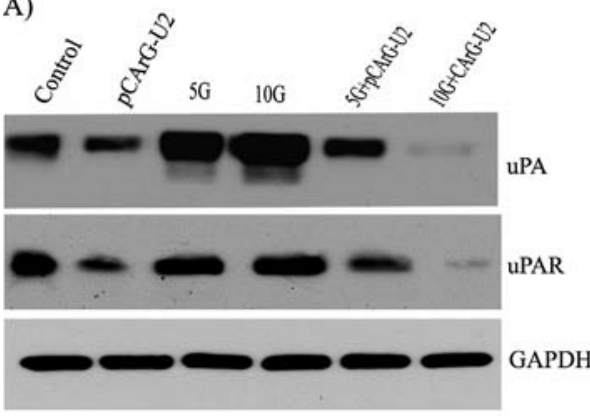

B)

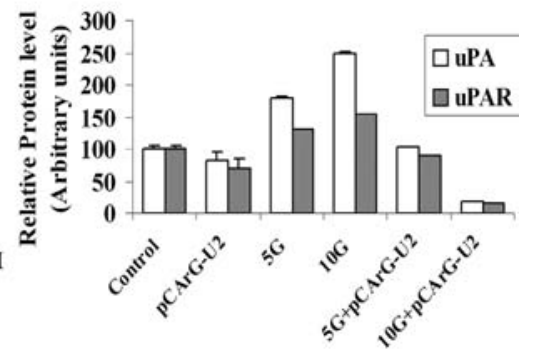

D)

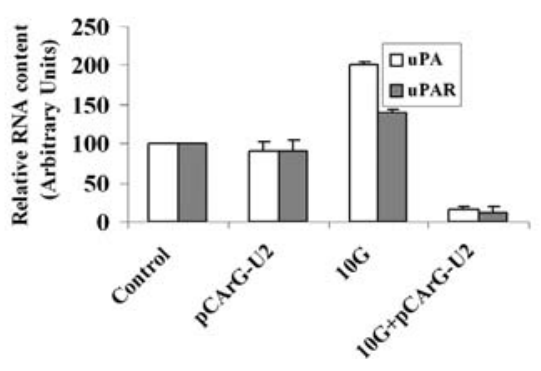

Figure 1. uPA and uPAR are knocked down in a radiation-inducible manner. (A) IOMM-Lee cells were transfected with pCArG-U2 and 24 h later, treated with 5 and $10 \mathrm{~Gy}$. Non-transfected cells were maintained as controls. Cell lysates were collected and equal amounts of proteins were subjected to immunoblotting with uPA and UPAR antibodies. (B) Densitometric analysis of uPA and uPAR Western blots. (C) IOMM-Lee cells were transfected with pCArG-U2 and irradiated with 10 Gy. Forty-eight hours after transfection, total RNA was extracted from the cells as per standard protocols. Reverse transcription PCR analysis was performed using primers specific for uPA, uPAR and GAPDH. (D) Densitometric analysis of relative transcript levels of uPA and UPAR. Results from three independent experiments are shown as means $\pm \mathrm{SD}(\mathrm{p}<0.05)$.

fected IOMM Lee cells with different concentrations of $\mathrm{H}_{2} \mathrm{O}_{2}$. Western blot analysis showed obvious silencing of uPA and uPAR with increasing concentration of $\mathrm{H}_{2} \mathrm{O}_{2}$ (Fig. 2A) when compared to the untreated cells, confirming oxidative damagemediated induction. Quantitative analysis of the transfected cells that were treated with $150 \mu \mathrm{M} \mathrm{H}_{2} \mathrm{O}_{2}$ showed $>80$ and $50 \%$ decrease in uPA and uPAR, respectively (Fig. 2B). In addition, pre-treatment of the transfected IOMM Lee cells with N-acetyl-L-cysteine did not show uPA and UPAR siRNA expression even after irradiation (Fig. 2C), thereby further confirming the oxidative damage-mediated functioning of CArG elements. Densitometric analysis did not show a significant difference between UPA and UPAR levels in transfected and non-transfected cells that were pre-treated with NAC (Fig. 2D).

Radiation-induced expression of $u P A$ and $U P A R$ siRNA decreased survival and induced apoptosis. Transfection of IOMM-Lee cells with pCArG-U2 induced a marked change in the morphological characteristics of the cells within the experimental time period (data not shown). Based on these observations, we performed cell proliferation assays and Western blot analysis for the expression of X-linked inhibitor of apoptosis protein (XIAP) and cleavage of poly ADPribose polymerase (PARP). MTT assay revealed that the majority of the transfected and irradiated cells showed no significant difference in proliferation. However, there was a significant inhibition of proliferation in transfected and irradiated cells when compared to control, transfected and irradiated cells (Fig. 3A). Further, we found that transfected and irradiated cells showed distinct cleavage of PARP, which is a downstream effector of caspases, and also a significant decrease in XIAP, which indicates the presence of apoptotic events in transfected and irradiated IOMM Lee cells (Fig. 3B). As shown in Fig. 3B, the 85-kDa prominent cleaved fragment of PARP-1 was detected in transfected and irradiated cells when compared to normal, transfected or irradiated control cells.

pCArG-U2 blocks radiation-stimulated migration and invasion. Noting that irradiation induced uPA and uPAR expression in cells, we next analyzed the migratory and invasive abilities of the IOMM-Lee cells. Transwell migration assays showed an increase in the migration properties of IOMM Lee cells in the irradiated treatment groups as compared to the controls (Fig. 4A). Migration of the pCArGU2-transfected cells was markedly diminished by $>50 \%$ in the irradiated cells as compared to non-irradiated cells (Fig. 4A). Matrigel invasion assay revealed a trend with irradiated cells showing a slight increase in the invasive potential when compared to the non-irradiated cells (Fig. 4B). However, pCArG-U2-transfected cells in the irradiated groups showed very poor invasion. Quantitative determination of invasion confirmed that IOMM-Lee cells transfected with pCArG-U2 invaded $<20 \%$ with irradiated cells but $>85 \%$ of inhibition of invaded cells with pCArG-U2 plus irradiation compared to controls (Fig. 4C).

Immunocytochemistry reveals decreased $U P A$ and $u P A R$ expression. As evident with the protein and RNA level 


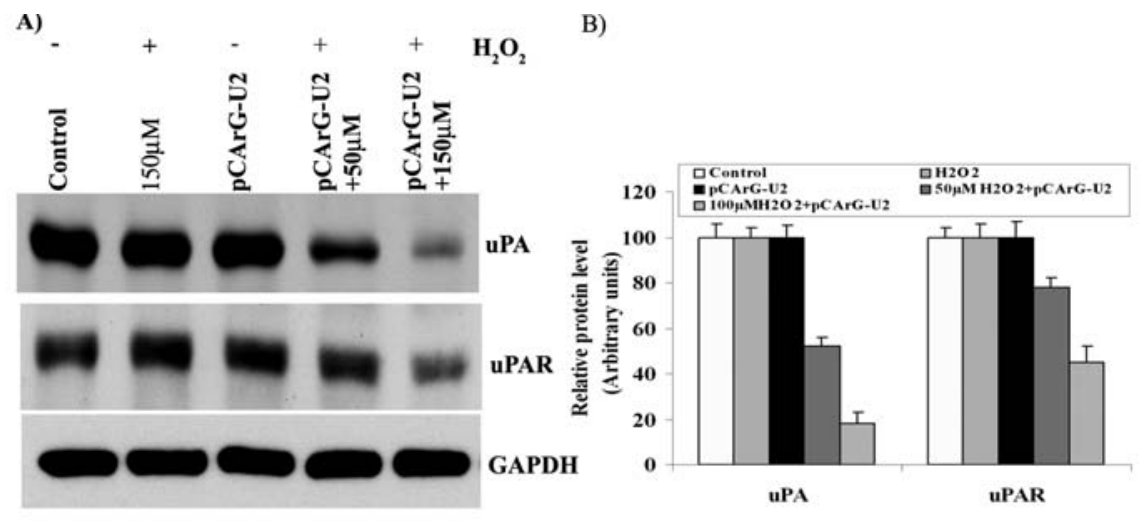

B)

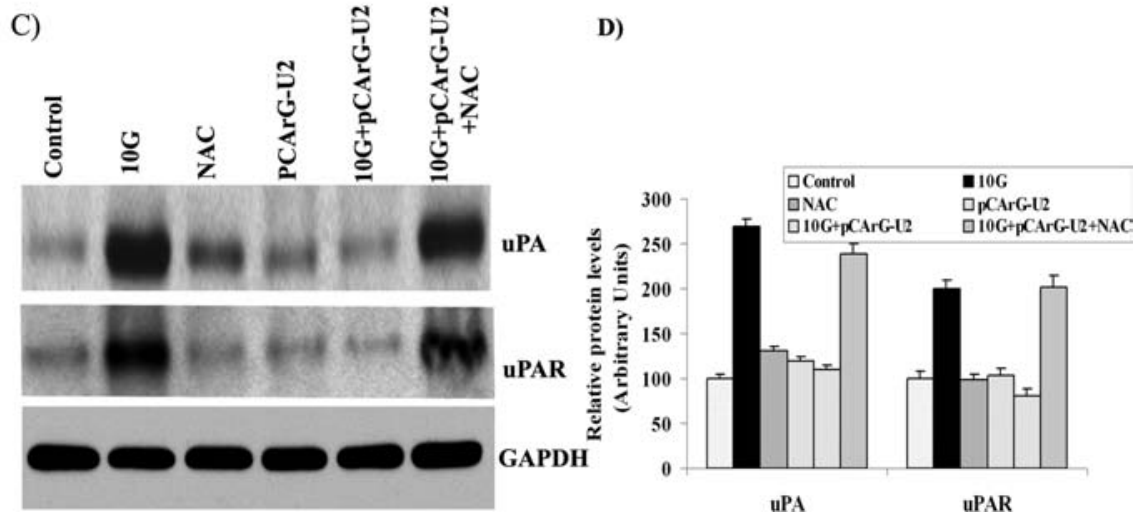

Figure 2. The inducibility of pCArG-U2 is mediated by oxidative damage. (A) IOMM-Lee cells were transfected with pCArG-U2, and after $24 \mathrm{~h}$, treated with different concentrations of $\mathrm{H}_{2} \mathrm{O}_{2}$ for another $24 \mathrm{~h}$. Cell lysates were subjected to Western blot analysis using uPA and uPAR antibodies. (B) Quantification of uPA and uPAR levels in various treatment groups from the Western blots. (C) IOMM-Lee cells were transfected with pCArG-U2 and treated with $30 \mathrm{mM}$ $\mathrm{N}$-acetyl L-cysteine for $45 \mathrm{~min}$ before radiation treatment with $10 \mathrm{~Gy}$. Twenty-four hours after radiation treatment, cell lysates were subjected to Western blotting with uPA and uPAR antibodies. (D) Densitometric analysis of Western blots. Results from three independent experiments are shown as means \pm SD $(\mathrm{p}<0.05)$.

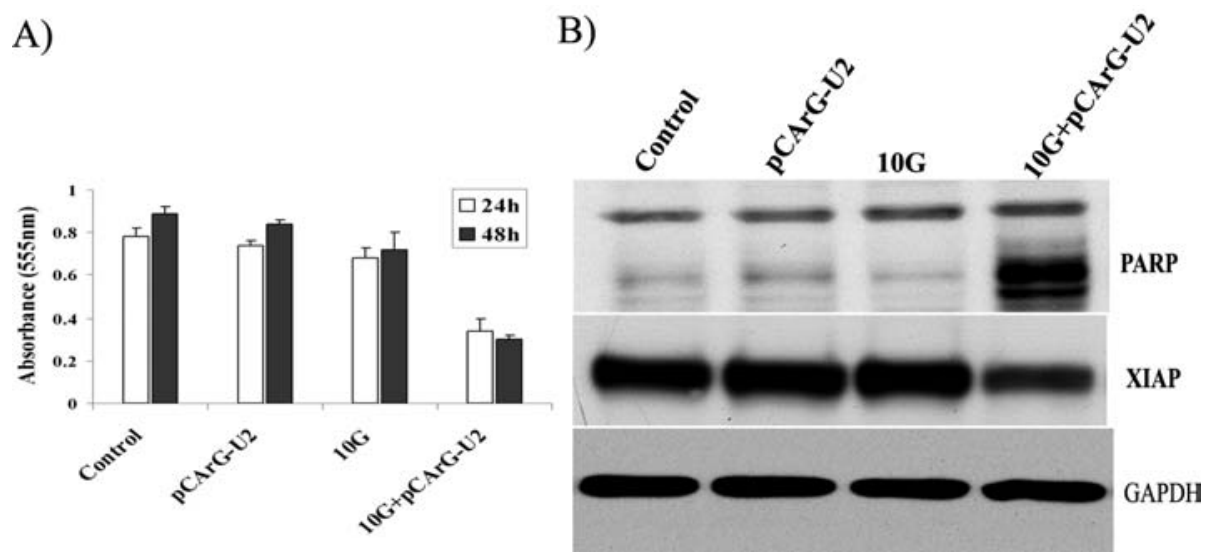

Figure 3. Transfection with pCArG-U2 induces apoptosis in a radiation-inducible manner. (A) IOMM-Lee cells were transfected with pCArG-U2 and irradiated with $10 \mathrm{~Gy}$ after $12 \mathrm{~h}$. Six hours later, cells were trypsinized, counted and seeded at $5 \times 10^{3}$ cells per well in 96 -well plates $(8$ wells per treatment group). After the indicated periods of incubation, MTT assay was performed as described in Materials and methods, and absorbance values were plotted against the time periods. Data shown are mean \pm SD from three different experiments $(\mathrm{p}<0.05)$. (B) Cell lysates from pCArG-U2-transfected, irradiated and control cells were used for immunoblot analysis for PARP cleavage and XIAP expression levels using specific antibodies.

decrease in UPA and uPAR in the cell extracts, we next studied the immunoreactivity of the cells under various conditions as described above with uPA and uPAR antibodies. We observed intense staining for UPA and UPAR in the irradiated IOMM Lee cells as compared to the control cells (Fig. 5A). We also observed a marked decrease in uPA and UPAR staining in the pCArG-U2-transfected and irradiated cells (Fig. 5A) when compared to cells treated 
A)

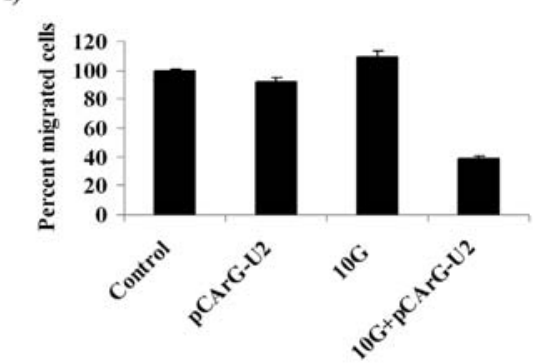

B)

Control

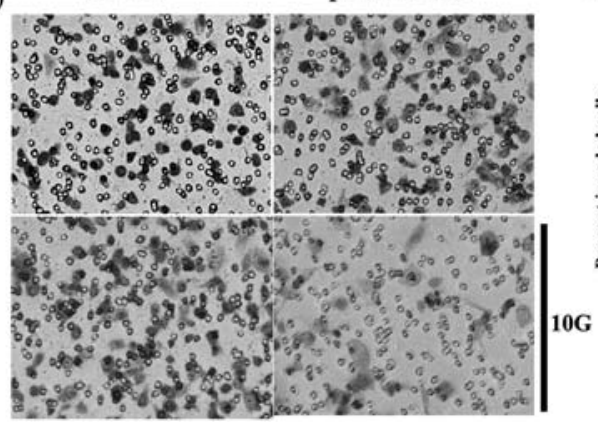

C)

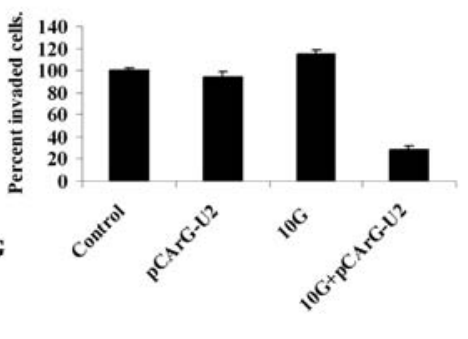

Figure 4. Knockdown of uPA and uPAR reduces migration and invasion in a radiation-inducible manner. (A) IOMM-Lee cells were transfected with pCArG$\mathrm{U} 2$ and irradiated after $24 \mathrm{~h}$. Untreated cells were also maintained to serve as the control. Immediately after radiation treatment, $5 \mathrm{x} 10^{4}$ cells were transferred to the upper chamber of $8 \mu \mathrm{M}$ transwell insert and maintained for another $24 \mathrm{~h}$ in serum-free media with complete medium in the lower chamber. Cell migration was computed as the relative number of treated cells migrated compared to the respective controls groups after staining. Values are mean \pm SD from three different experiments ( $<0.05)$. (B) IOMM-Lee cells were transfected with pCArG-U2 and irradiated at $10 \mathrm{~Gy} 24 \mathrm{~h}$ after transfection. Untreated cells (mock) were also maintained to serve as the control. After irradiation, the cells were trypsinized and $1 \times 10^{5}$ cells from each treatment group and controls were cultured in the upper chamber of a transwell insert coated with Matrigel $(1 \mathrm{mg} / \mathrm{ml})$. Representative pictures were taken after $24 \mathrm{~h}$ of incubation. (C) The number of cells in three different fields for each sample was counted. The percent invasion of cells transfected with pCArG-U2 was analyzed and compared with the untreated (mock) cells. Values are mean \pm SD from three different experiments $(\mathrm{p}<0.05)$.

with radiation alone, thereby confirming the radiationinducible nature of pCArG-U2.

pCArG-U2 decreased tumor size, $u P A$ and $u P A R$ levels in pre-established tumors. To correlate the in vitro results with in vivo experiments, we analyzed the expression of uPA and uPAR in the tumor tissues using immunohistochemical staining of the paraffin-embedded sections. Antibodies against UPA and UPAR showed strong immunoreactivity in the tissue sections of IOMM-Lee meningioma intracranial tumors raised in nude mice. Confirming the results of the in vitro experiments, the highest immunoreactivity for both UPA and UPAR was seen in the irradiated tumors. In contrast, pCArG-U2 treatment specifically inhibited the expression of UPA and uPAR in the irradiated tumors (Fig. 5B). Hematoxylin and eosin staining revealed a marked decrease in the tumor size in the brain sections of the animals treated with radiation and pCArG-U2 compared to the respective control groups (Fig. 5C)

\section{Discussion}

Our previous studies with siRNA constructs specifically targeting extracellular proteases revealed their usefulness in therapeutic strategies against meningioma, glioma and breast cancer (18,26-28). However, the heterogeneity and evolution of resistance among tumor cells illustrate the need for combining therapeutic modalities. The success of targeted cancer therapy relies on the ability of the agent to reach the target in sufficient concentration with limited toxicity to surrounding tissues. Despite advancements in the radiation treatments for various tumors, radioresistance has been well documented. In fact, previous studies have shown elevated expression of uPA and UPAR as well as a significant increase in invasive and migration behaviors in IOMM-Lee cells. Radiation treatment is well documented to be connected to development of radiation-induced meningioma (RIM) proving the long-term ill effects caused by the radiation treatment regimens $(29,30)$. Nevertheless, the precision of radiation treatment presents an opportunity to utilize tumor-specific promoters and inducible promoter systems. Furthermore, ionizing radiation has also been recently shown to enhance vascular tone through the induction of nitric oxide production by endothelial cells, leading to facilitated delivery and enhanced transgene expression (31). We hypothesize that approaches designed to express radiation-inducible gene therapy products will be synergistic, thereby improving tumor eradication while limiting toxicity to the normal tissue.

Chimeric promoters based on the cytomegalovirus immediate early (CMV IE) basal gene promoter have shown robust radiation inducibility $(3,13,32)$. The first radiation-inducible promoter system used in combination with gene therapy involved the EGR-1 promoter with the gene for the radiosensitizing cytokine TNF- $\alpha$, which resulted in increased tumor growth inhibition when compared with tumors treated with radiation alone (7). Promoters containing tandem repeats of 
A)

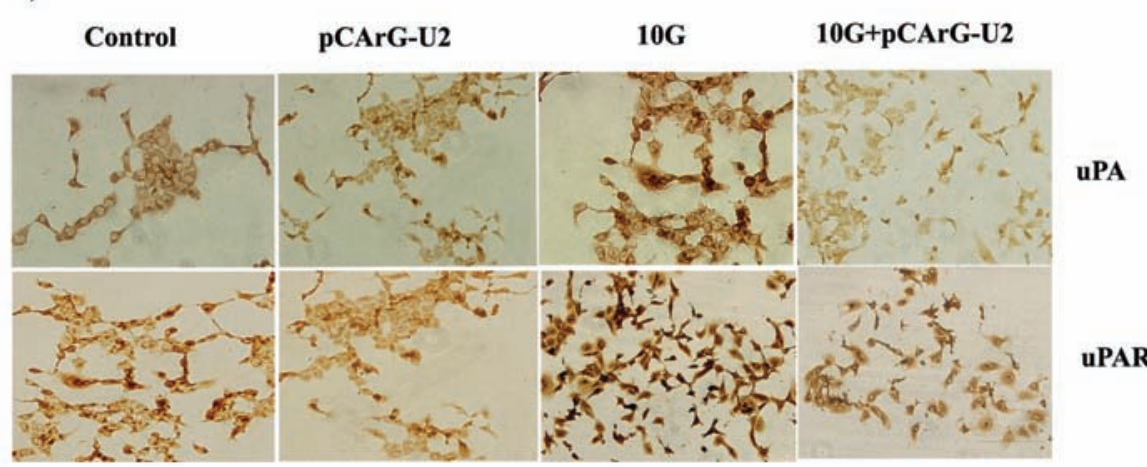

B)

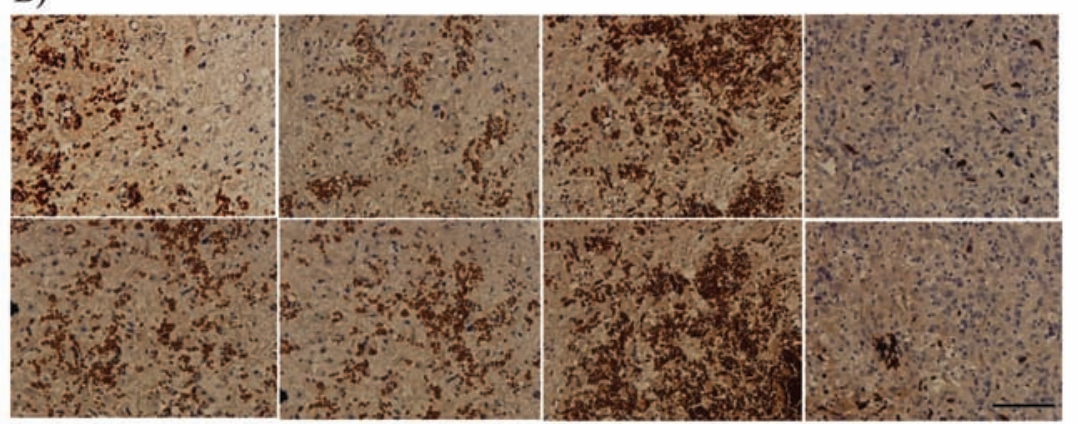

uPA

C)

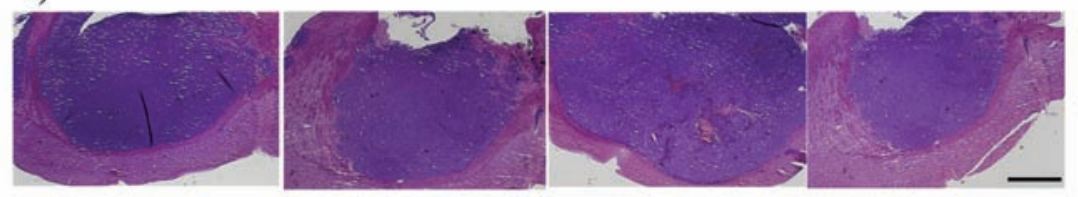

H\&E

Figure 5. Immunocytochemistry and immunohistochemistry reveal decreased uPA and uPAR. (A) IOMM-Lee cells were seeded onto chamber slides and transfected with pCArG-U2. Twenty-four hours after transfection, cells were irradiated and incubated for another $24 \mathrm{~h}$. The cells were fixed, permeabilized and subjected to immunostaining with antibodies for uPA and uPAR. The expression levels of uPA and uPAR were analyzed in different microscopic fields of the slides and representative photographs are shown ( $\mathrm{n}=5$, bar represents $20 \mu \mathrm{m})$. (B) Immunohistochemical analyses for uPA and uPAR in the paraffinembedded sections of intracranial tumors implanted with IOMM-Lee cells. Slides were counterstained with hematoxylin for nuclear staining. Pictures are representative of different treatment groups $(\mathrm{n}=5$, bar represents $50 \mu \mathrm{m})$. (C) Brain sections from the all the groups of animals were subjected to H\&E staining to visualize the tumor size and representative pictures are shown $(\mathrm{n}=5$, bar represents $500 \mu \mathrm{m})$.

CArG sequences demonstrated greater inducibility and lower basal activity than the wild-type EGR-1 promoter despite containing the same number of elements. The synthetic promoter was shown to be induced by single-radiation doses as low as $1 \mathrm{~Gy}$ in MCF-7 as well as in U87-MG cells (3). Dose-dependent increase of inducible transgene expression has been reported with caspase 8 (13). We observed a similar increase for the expression of siRNAs with 5 and $10 \mathrm{~Gy}$. Also, fractionated radiation has been shown to be effective compared to a single dose in driving transgene expression (13). Our results also demonstrate that pCArG-U2 induced apoptosis in the irradiated cells to a greater extent, thereby showing the precision of the system. In agreement with our previous report, radiation-induced knockdown of uPA and UPAR also lead to the significant decrease in the cell proliferation, invasion, migration of IOMM-Lee cells in vitro. However, the transfected cells that are not irradiated did not show any significant decrease compared to the controls. The inhibition of tumor growth and decrease in expression of UPA and UPAR in tumor sections proved the efficacy of the system in in vivo.

Moreover, previous mechanistic studies of the EGR-1 promoter have identified a role for the activation of the promoter in response to reactive oxygen species. The induction of CArG elements by hydrogen peroxide (33) and cisplatin (34) have been shown to be quantitatively similar to that achievable by ionizing radiation. The results of the present study with $\mathrm{H}_{2} \mathrm{O}_{2}$ treatment confirm past studies and depict the versatile function of CArG sequences. In addition, other groups have reported that expression of EGR-1 is abundant in some malignancies and is involved in apoptosis (35), suggesting that the CArG elements might be convenient for targeted gene therapies in other situations as well.

In conclusion, the results of the present study show that a combination approach using uPA and UPAR siRNA therapy along with radiation treatment produced target-specific effects with regard to inducing apoptosis. For the first time, we are reporting a strategy to express siRNA in a radiationinducible fashion for the targeted knockdown of molecules.

\section{Acknowledgements}

We thank Shellee Abraham for assistance in the manuscript preparation and Diana Meister and Sushma Jasti for the review. This research was funded by NINDS NS061835 to Jasti S. Rao. 


\section{References}

1. Park CM, Park MJ, Kwak HJ, Lee HC, Kim MS, Lee SH, Park IC Rhee $\mathrm{CH}$ and Hong SI: Ionizing radiation enhances matrix metalloproteinase-2 secretion and invasion of glioma cells through Src/epidermal growth factor receptor-mediated p38/Akt and phosphatidylinositol 3-kinase/Akt signaling pathways. Cancer Res 66: 8511-8519, 2006.

2. Zhai GG, Malhotra R, Delaney M, Latham D, Nestler U, Zhang M, Mukherjee N, Song Q, Robe P and Chakravarti A: Radiation enhances the invasive potential of primary glioblastoma cells via activation of the Rho signaling pathway. J Neurooncol 76: 227-237, 2006

3. Scott SD, Marples B, Hendry JH, Lashford LS, Embleton MJ, Hunter RD, Howell A and Margison GP: A radiation-controlled molecular switch for use in gene therapy of cancer. Gene Ther 7: 1121-1125, 2000 .

4. Worthington J, McCarthy HO, Barrett E, Adams C, Robson T and Hirst DG: Use of the radiation-inducible WAF1 promoter to drive iNOS gene therapy as a novel anti-cancer treatment. J Gene Med 6: 673-680, 2004.

5. Marignol L, Coffey M, Hollywood D and Lawler M: Radiation to control transgene expression in tumors. Cancer Biol Ther 6: 1005-1012, 2007.

6. Hallahan DE, Sukhatme VP, Sherman ML, Virudachalam S, Kufe D and Weichselbaum RR: Protein kinase C mediates X-ray inducibility of nuclear signal transducers EGR1 and JUN. Proc Natl Acad Sci USA 88: 2156-2160, 1991.

7. Weichselbaum RR, Hallahan DE, Beckett MA, Mauceri HJ, Lee H, Sukhatme VP and Kufe DW: Gene therapy targeted by radiation preferentially radiosensitizes tumor cells. Cancer Res 54: 4266-4269, 1994.

8. Datta R, Rubin E, Sukhatme V, Qureshi S, Hallahan D, Weichselbaum RR and Kufe DW: Ionizing radiation activates transcription of the EGR1 gene via CArG elements. Proc Natl Acad Sci USA 89: 10149-10153, 1992.

9. McCarthy HO, Worthington J, Barrett E, Cosimo E, Boyd M, Mairs RJ, Ward C, McKeown SR, Hirst DG and Robson T: p21(WAF1)-mediated transcriptional targeting of inducible nitric oxide synthase gene therapy sensitizes tumours to fractionated radiotherapy. Gene Ther 14: 246-255, 2007.

10. Boothman DA, Lee IW and Sahijdak WM: Isolation of an X-rayresponsive element in the promoter region of tissue-type plasminogen activator: potential uses of X-ray-responsive elements for gene therapy. Radiat Res 138: S68-S71, 1994.

11. Greco O, Joiner MC, Doleh A, Powell AD, Hillman GG and Scott SD: Hypoxia- and radiation-activated Cre/loxP 'molecular switch' vectors for gene therapy of cancer. Gene Ther 13: 206$215,2006$.

12. Weichselbaum RR, Kufe DW, Hellman S, Rasmussen HS, King CR, Fischer PH and Mauceri HJ: Radiation-induced tumour necrosis factor-alpha expression: clinical application of transcriptional and physical targeting of gene therapy. Lancet Oncol 3: 665-671, 2002.

13. Tsurushima H, Yuan X, Dillehay LE and Leong KW: Radiationinducible caspase- 8 gene therapy for malignant brain tumors. Int J Radiat Oncol Biol Phys 71: 517-525, 2008.

14. Joki T, Nakamura M and Ohno T: Activation of the radiosensitive EGR-1 promoter induces expression of the herpes simplex virus thymidine kinase gene and sensitivity of human glioma cells to ganciclovir. Hum Gene Ther 6: 1507-1513, 1995.

15. Scott SD, Joiner MC and Marples B: Optimizing radiationresponsive gene promoters for radiogenetic cancer therapy. Gene Ther 9: 1396-1402, 2002.

16. Coulter JA, McCarthy HO, Worthington J, Robson T, Scott S and Hirst DG: The radiation-inducible pE9 promoter driving inducible nitric oxide synthase radiosensitizes hypoxic tumour cells to radiation. Gene Ther 15: 495-503, 2008.

17. Gondi CS, Lakka SS, Dinh D, Olivero W, Gujrati M and Rao JS: Downregulation of uPA, UPAR and MMP-9 using small, interfering, hairpin RNA (siRNA) inhibits glioma cell invasion, angiogenesis and tumor growth. Neuron Glia Biol 1: 165-176, 2004

18. Kargiotis O, Chetty C, Gogineni V, Gondi CS, Pulukuri SM, Kyritsis AP, Gujrati M, Klopfenstein JD, Dinh DH and Rao JS uPA/uPAR downregulation inhibits radiation-induced migration, invasion and angiogenesis in IOMM-Lee meningioma cells and decreases tumor growth in vivo. Int J Oncol 33: 937-947, 2008.
19. Pulukuri SM, Gondi CS, Lakka SS, Jutla A, Estes N, Gujrati M and Rao JS: RNA Interference-directed knockdown of urokinase plasminogen activator and urokinase plasminogen activator receptor inhibits prostate cancer cell invasion, survival, and tumorigenicity in vivo. J Biol Chem 280: 36529-36540, 2005.

20. Duffy MJ, Maguire TM, McDermott EW and O'Higgins N: Urokinase plasminogen activator: a prognostic marker in multiple types of cancer. J Surg Oncol 71: 130-135, 1999.

21. Steiner E, Pollow K, Hasenclever D, Schormann W, Hermes M, Schmidt M, Puhl A, Bruiport M, Bauer A, Petry IB, Koelbl H and Hengstler JG: Role of uorkinase-type plasminogen activator (uPA) and plasminogen activator inhibitor type 1 (PAI-1) for prognosis in endometrial cancer. Gynecol Oncol 108: 569-576, 2008.

22. Gondi CS and Rao JS: Therapeutic potential of siRNAmediated targeting of urokinase plasminogen activator, its receptor, and matrix metalloproteinases. Methods Mol Biol 487: 267-281, 2009.

23. Chomczynski P and Sacchi N: Single-step method of RNA isolation by acid guanidinium thiocyanate-phenol-chloroform extraction. Anal Biochem 162: 156-159, 1987

24. Pulukuri SM and Rao JS: Small interfering RNA directed reversal of urokinase plasminogen activator demethylation inhibits prostate tumor growth and metastasis. Cancer Res 67: 6637-6646, 2007.

25. Gondi CS, Lakka SS, Yanamandra N, Siddique K, Dinh DH, Olivero WC, Gujrati M and Rao JS: Expression of antisense uPAR and antisense uPA from a bicistronic adenoviral construct inhibits glioma cell invasion, tumor growth, and angiogenesis. Oncogene 22: 5967-5975, 2003.

26. Gogineni VR, Kargiotis O, Klopfenstein JD, Gujrati M, Dinh DH and Rao JS: RNAi-mediated downregulation of radiationinduced MMP-9 leads to apoptosis via activation of ERK and Akt in IOMM-Lee cells. Int J Oncol 34: 209-218, 2009.

27. Gondi CS, Lakka SS, Dinh DH, Olivero WC, Gujrati M and Rao JS: Intraperitoneal injection of an hpRNA-expressing plasmid targeting uPAR and uPA retards angiogenesis and inhibits intracranial tumor growth in nude mice. Clin Cancer Res 13: 4051-4060, 2007.

28. Kunigal S, Lakka SS, Gondi CS, Estes N and Rao JS: RNAimediated downregulation of urokinase plasminogen activator receptor and matrix metalloprotease- 9 in human breast cancer cells results in decreased tumor invasion, angiogenesis and growth. Int J Cancer 121: 2307-2316, 2007.

29. DeTommasi A, Occhiogrosso M, De TC, Cimmino A, Sanguedolce F and Vailati G: Radiation-induced intracranial meningiomas: review of six operated cases. Neurosurg Rev 28: 104-114, 2005.

30. Umansky F, Shoshan Y, Rosenthal G, Fraifeld S and Spektor S: Radiation-induced meningioma. Neurosurg Focus 24: E7, 2008.

31. Sonveaux P, Frerart F, Bouzin C, Brouet A, Dewever J, Jordan BF, Gallez B and Feron O: Irradiation promotes Akt-targeting therapeutic gene delivery to the tumor vasculature. Int J Radiat Oncol Biol Phys 67: 1155-1162, 2007.

32. Marples B, Scott SD, Hendry JH, Embleton MJ, Lashford LS and Margison GP: Development of synthetic promoters for radiation-mediated gene therapy. Gene Ther 7: 511-517, 2000.

33. Datta R, Taneja N, Sukhatme VP, Qureshi SA, Weichselbaum R and Kufe DW: Reactive oxygen intermediates target $\mathrm{CC}(\mathrm{A} / \mathrm{T})$ $6 \mathrm{GG}$ sequences to mediate activation of the early growth response 1 transcription factor gene by ionizing radiation. Proc Natl Acad Sci USA 90: 2419-2422, 1993.

34. Park JO, Lopez CA, Gupta VK, Brown CK, Mauceri HJ, Darga TE, Manan A, Hellman S, Posner MC, Kufe DW and Weichselbaum RR: Transcriptional control of viral gene therapy by cisplatin. J Clin Invest 110: 403-410, 2002.

35. Zagurovskaya M, Shareef MM, Das A, Reeves A, Gupta S, Sudol M, Bedford MT, Prichard J, Mohiuddin M and Ahmed MM: EGR-1 forms a complex with YAP-1 and upregulates Bax expression in irradiated prostate carcinoma cells. Oncogene 28: 1121-1131, 2009. 